PARTECIPANZA

(numbers along branches represent the number of generations; $\mathrm{NG}=$ total number of generations).

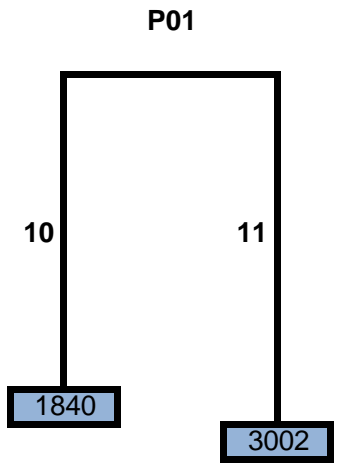

$N G=21$
P02

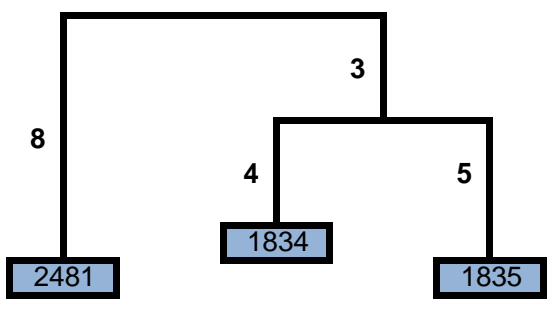

$N G=20$
P03

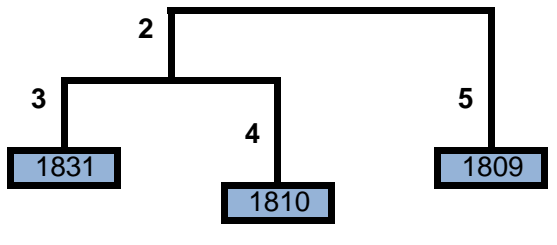

$N G=14$

P05

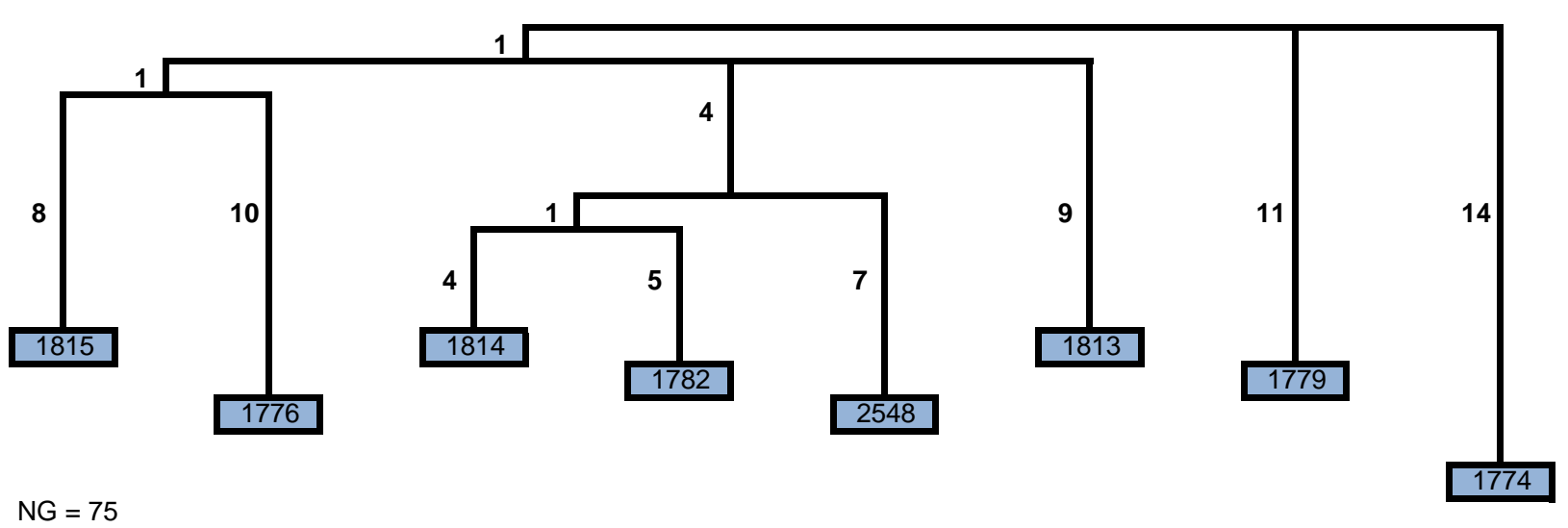

$N G=75$

P04

P06

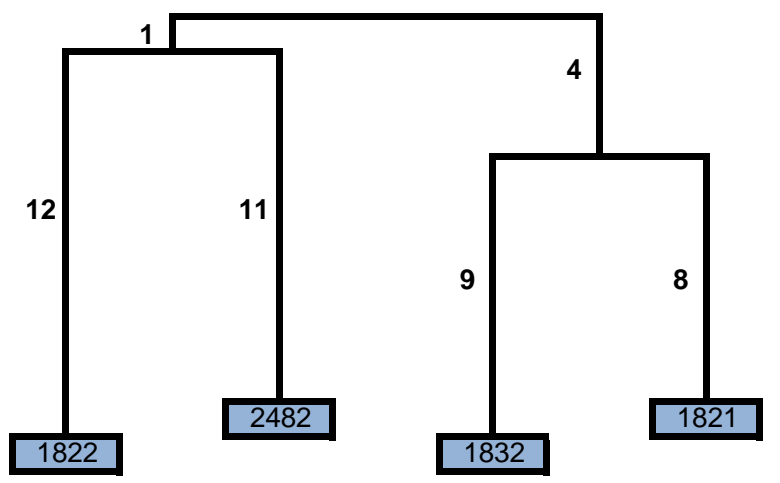

$N G=45$ 

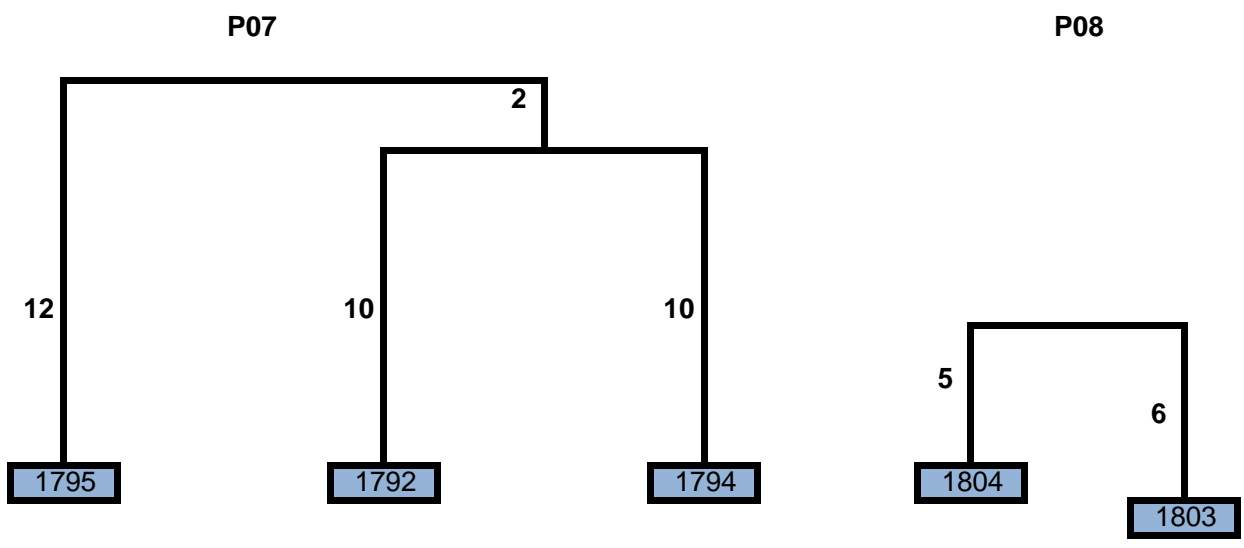

P09

$N G=34$

$N G=11$

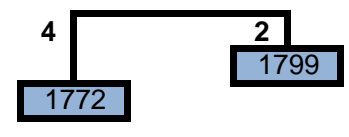

$N G=6$

P10

P11

P12

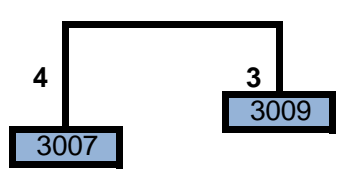

$N G=7$

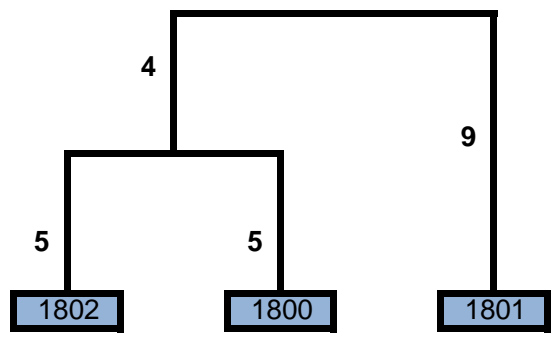

$N G=23$

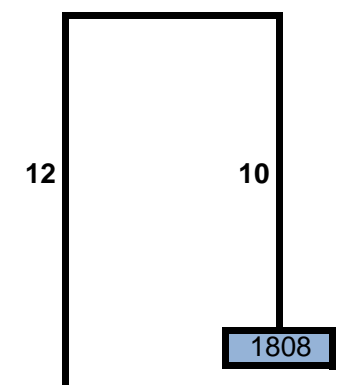

1807

$N G=22$
P13

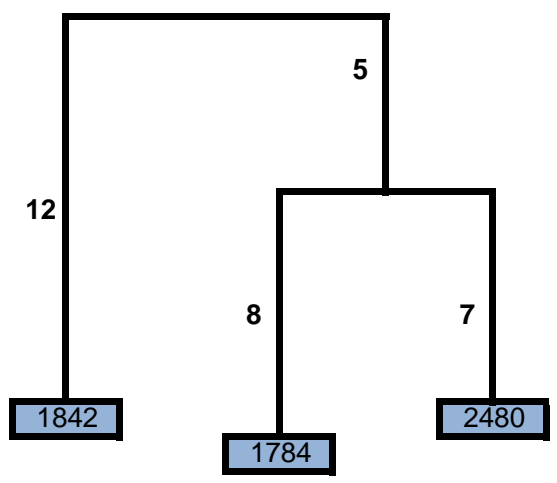

$N G=32$
P14

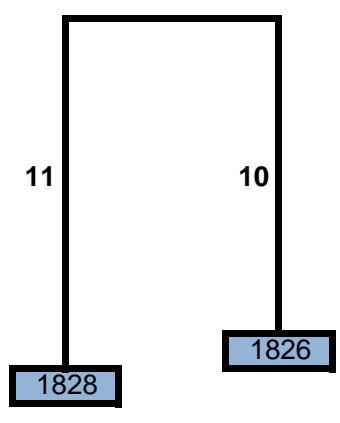

$N G=21$
P15

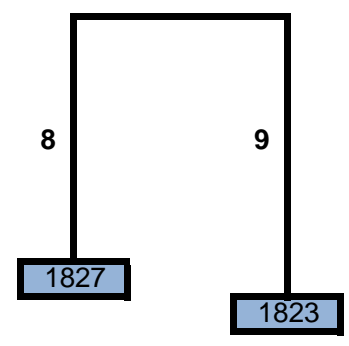

$N G=17$ 
PIEVEQUINTA

(numbers along branches represent the number of generations; $\mathrm{NG}=$ total number of generations).

G13

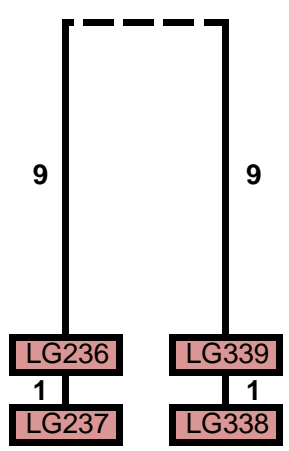

$N G=20$

G14

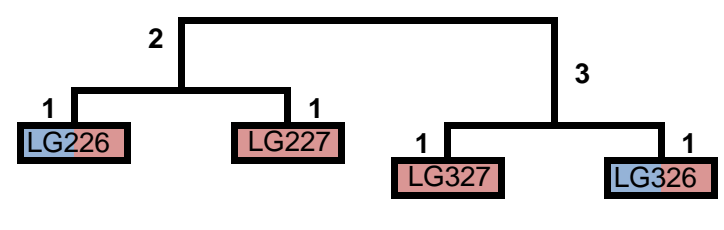

$N G=9$

G15

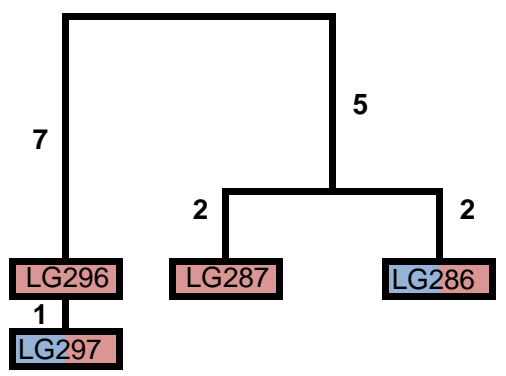

$N G=17$
G17

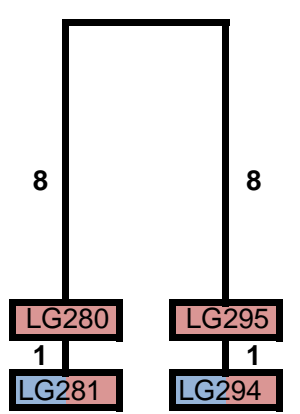

$N G=18$
G18

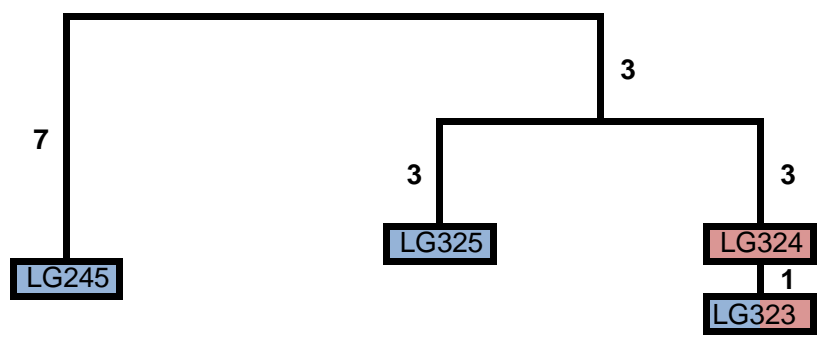

$N G=17$
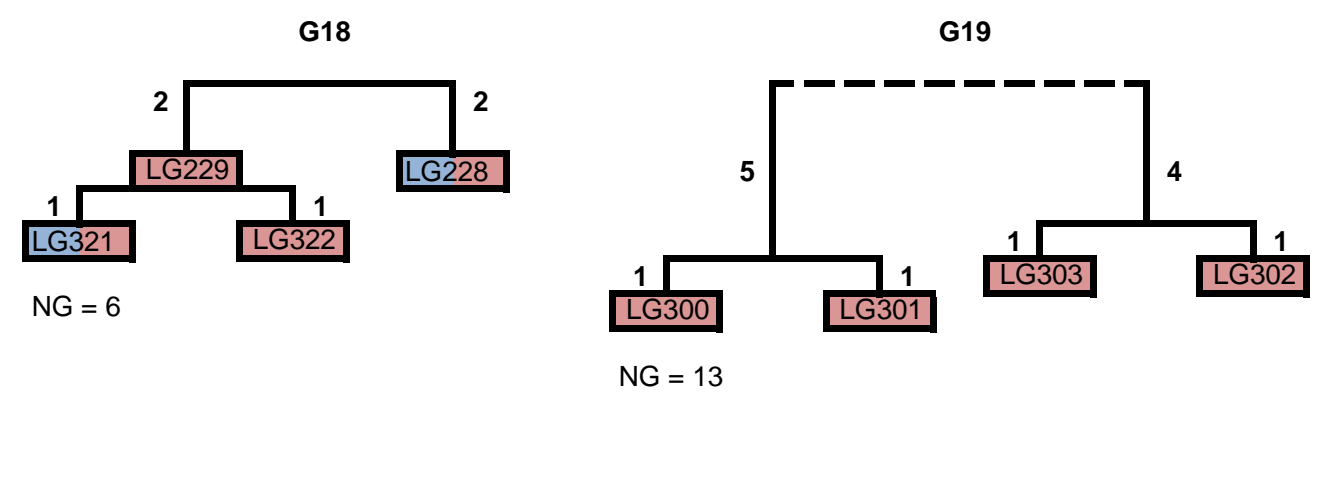

G20
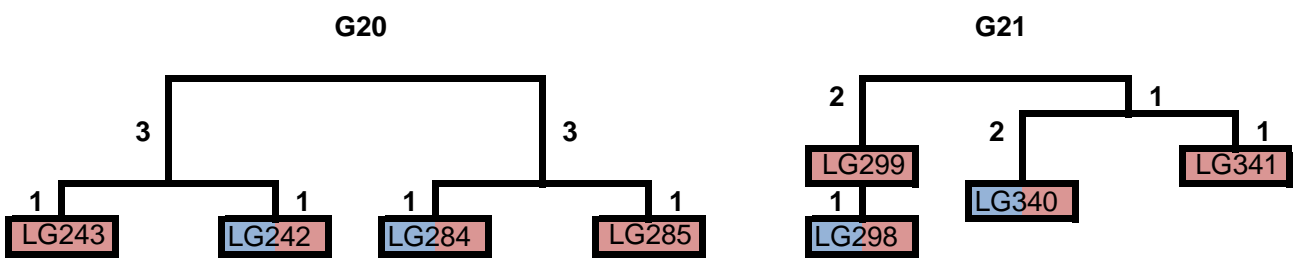

$N G=10$

$N G=7$ 

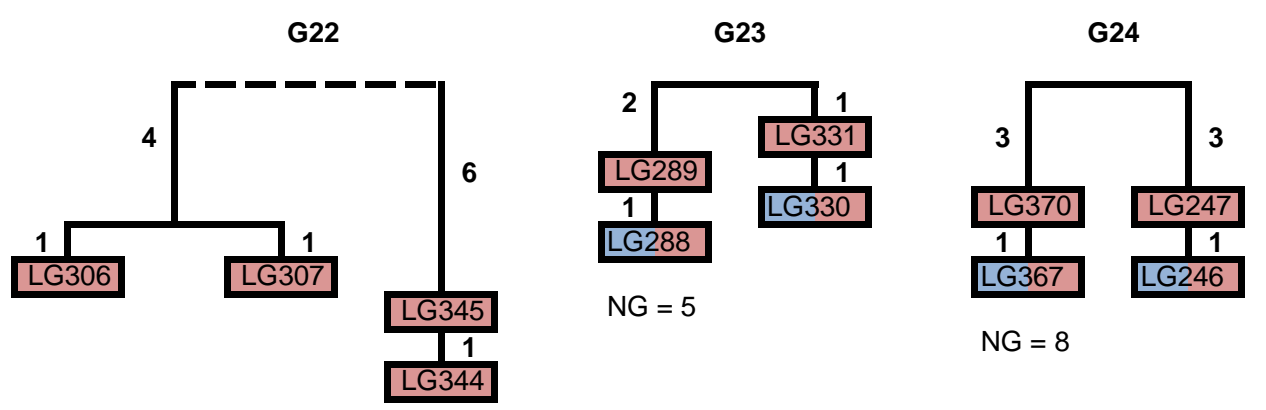

$N G=13$
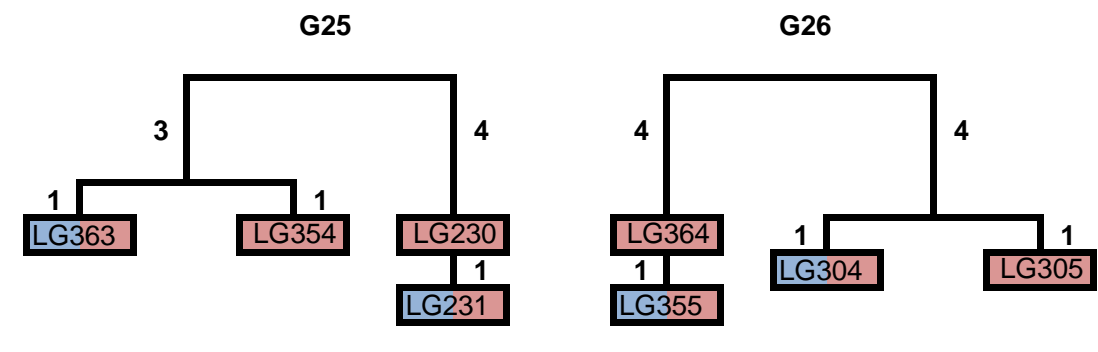

$N G=10$

$N G=11$

\section{COLOR CODES}

Individuals included in DATASET A

Individuals included in DATASET B

Individuals included both in DATASET A and DATASET B 